\title{
Impact of Variable Switching Frequency over Power Loss on Converter Topologies
}

\author{
C.Krishna Kumar ${ }^{1}$ Dr.A.NirmalKumar ${ }^{2}$ Dr.B.Karthikeyan ${ }^{3}$ R.Abinaya ${ }^{4}$ \\ 1. Assistant Professor, EEE Dept., Periyar Maniammai University, Vallam \\ 2. Head of the Department, Bannari Amman Institute of Technology, Sathyamangalam \\ 3. Associate Professor/EEE BITS Dubai campus, Dubai.
}

4. M.Tech, SRM

\begin{abstract}
This paper compares different topologies of DC-DC converters for levels of mitigation of EMI using a RCD snubber for each. This paper proposes the design and simulation of a Buck, Cuk and the Boost converter using the software PSPICE. The circuit was constructed on PSPICE and the output voltage of the converter is simulated for different switching frequency. The simulated output was then studied for different switching frequencies keeping duty cycle constant, and EMI was found in the output due to switching of the MOSFET. In order to minimize this interference a RCD snubber circuit was designed in PSPICE across the MOSFET of the converter. The output and simulations of these three topologies were then studied in comparison to the output of these converters without snubber circuit.
\end{abstract}

\section{INTRODUCTION}

All power electronics equipments generate and emit unwanted electrical signals (EMI noise) that can lead to performance degradation of itself and other nearby electrical/electronic equipments. They generate high frequency conducted and radiated EMI noise and draw distorted line currents due to the sharp edges of the switching waveforms with high $\mathrm{dv} / \mathrm{dt}$. The different topologies that are used for the production of SMPS and other biomedical instruments have more stringent EMC regulations. The ever increasing use of off-line power supplies that have taken place over the years has led to the adoption of standards in order to achieve an adequate harmonic performance. These standards contain regulations for low order harmonic content (current distortion, e.g. IEC555-2) and high-order harmonics (EMI, Electro Magnetic Interference). The most restrictive commercial standard concerned with conducted EMI is the VDE0871. This standard specifies the maximum allowable conducted EMI generated by a piece of equipment. Meanwhile, the requirements for measuring apparatus and measurement methods are outlined by CISPR Publication 16. This publication states that the bandwidth of measurement in the range from $10 \mathrm{kHz}$ to $150 \mathrm{kHz}$ is $200 \mathrm{~Hz}$. On the other hand, this bandwidth is $9 \mathrm{kHz}$ for frequency ranging from $150 \mathrm{kHz}$ to $30 \mathrm{MHz}$. This change in the bandwidth of measurement affects strongly the EM1 performance.

\section{ELECTROMAGNETIC INTERFERENCE}

The switches with the high $\mathrm{dv} / \mathrm{dt}$ and $\mathrm{di} / \mathrm{dt}$ switching slopes are the main sources of EMI. High rates of $\mathrm{dv} / \mathrm{dt}$ and parasitic capacitors to the ground are the reasons for common mode interference. Electromagnetic Interference (EMI) is an unwanted disturbance that affects an electrical circuit due to conducted EMI emission is interference that propagates through the metal conductors and cables. The interference sources are coupled onto the power cable to the equipment. In addition the interference may be coupled inductively or capacitively from another cable to the power cable. Conducted EMI emission is composed of two components commonly known as the differential mode and the common mode noise.

Conducted noise consists of two categories

2.1. Differential Mode Noise: It is measured between each power line and ground. Differential mode is due to magnetic coupling. Differential Mode noise attempts to dissipate its energy along any path from line to neutral. The transmission of the differential mode noise is through the input line to the utility system and through the DC network to the load on the power converter. Differential mode noise is present on both the input and output lines.

2.2. Common Mode Noise: It is measured between Line and ground. Common mode noise is due to stray capacitance. The transmission of common mode noise is entirely through parasitic or stray capacitors and stray electrical and magnetic fields. Common mode noise is present on both input and the common mode current flows into the parasitic capacitors between the power converter components and the protection earth. Since the common mode currents share most of their paths with other equipment, the level of EM1 emission from them is usually higher than that from the differential mode currents.

For this research, the effect of snubber circuit in the power loss reduction is analyzed for different switching frequency of Buck, Boost and Cuk converter.

\section{PSPICE SIMULATION CIRCUIT}

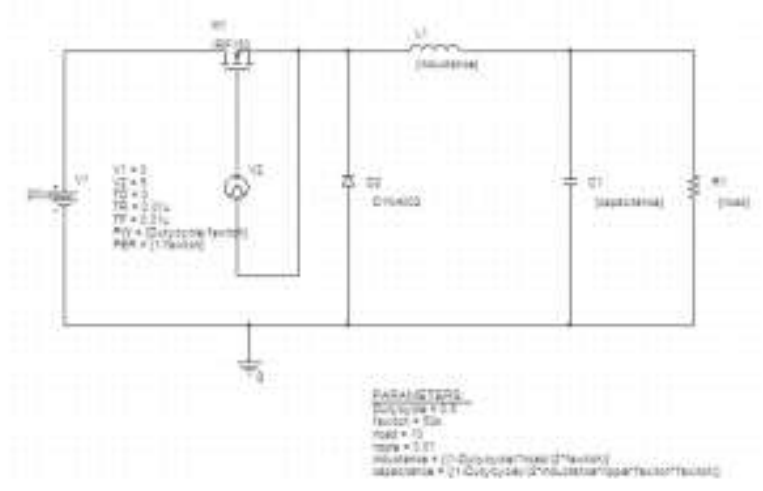

Figure 1: Buck Converter Circuit on PSPICE 
Figure 1 shows the simulation circuit of Buck converter in PSPICE. To design a converter the value of inductor and capacitor should be calculated, and the MOSFET and diode need to be selected. In order to do this, the switching frequency, duty cycle and the load resistance should be known.

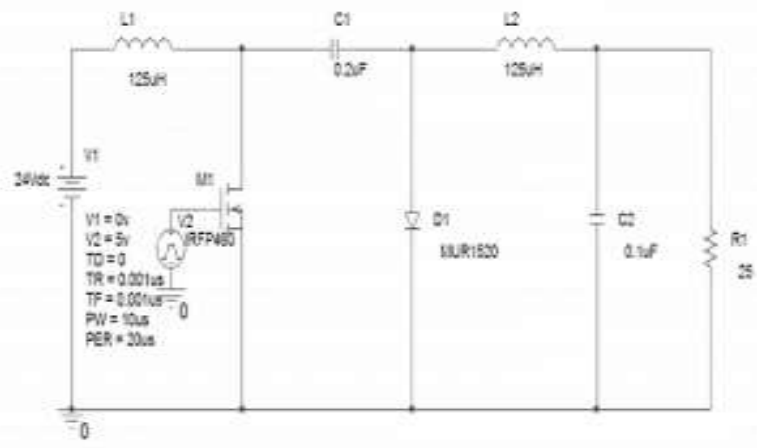

Figure 2. Simulation circuit of Cuk converter in PSPICE.

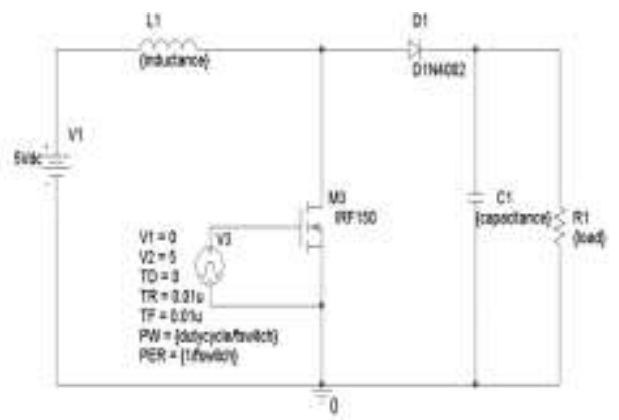

Figure 3.Simulation circuit of Boost converter in PSPICE.

\section{SNUBBER CIRCUIT}

The application of DC-DC converters appear in large numbers. Switching losses are high due to operation of the converters in hard switching mode. [1], [3] and [4]. The converter topologies could be realized as chip versions. For these advanced technologies the power losses must be properly evaluated and measures should be taken to reduce the losses effectively. The snubber circuits are usually placed in the converter structure to adjust the turn-on and turn-off losses. The switching-on snubber circuit is connected in series to limit the $d i / d t$ at turn-on. The switching-off snubber circuit is connected in parallel to limit the $d v / d t$ at turn-off.

The purpose of using Snubber circuits is to

$>$ Limit rate of rise of voltage across a switching device

$>$ Limit rate of rise of current flowing through a switching device

$>\quad$ Modify the switching trajectory

$>$ Reduce EMI

\subsection{RCD Snubber circuit on Cuk Converter}

The Cuk converter like all other hard-switched converters faces the problem of Electromagnetic Interference (EMI). In order to reduce the interference and hence increase the efficiency of the Cuk converter a snubber circuit is applied to the MOSFET. A RCD Snubber is used on the MOSFET, where the values of capacitor $\mathrm{C}$ and resistor $\mathrm{R}$ are determined by the formulae that follow-

$$
>C=\frac{I_{d} t_{f}}{2 V_{d s}}
$$

Where,

$t_{f}$ stands for Fall Time of the MOSFET,

$V_{d s}$ stands for Drain to Source Voltage,

$I_{d}$ stands for Drain Current.

The value of $\mathrm{C}$ which is determined is then used to calculate the value of resistor $\mathrm{R}$ as given below-

$$
>R=\frac{\tau}{C}
$$

Where $\tau$ stands for discharge time.

Here it is known that

$$
\begin{aligned}
& >t_{f}=100 \mathrm{~ns} ; \\
& >\quad V_{d s}=100 \mathrm{~V} ; \\
& >\quad I_{d}=12.318 * 1.1=13.55 \mathrm{~A}
\end{aligned}
$$

Hence capacitance $\mathrm{C}=6.75 \mathrm{nf}$.

Discharge time $=35 \mathrm{~ns}$

Hence resistance $\mathrm{R}=5.185=5 \mathrm{ohms}$ (approx)

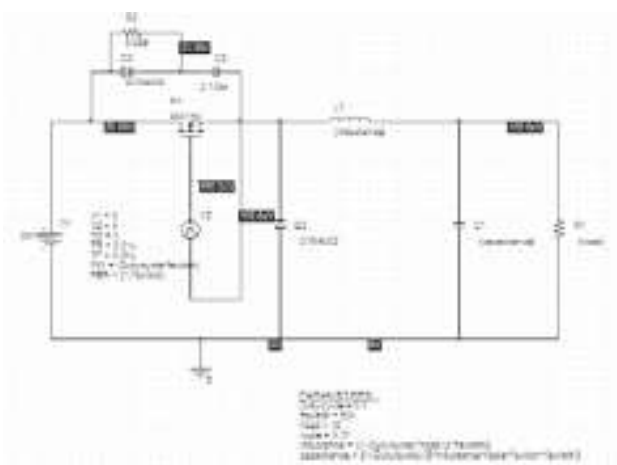

Figure 4: Buck Converter with snubber circuit

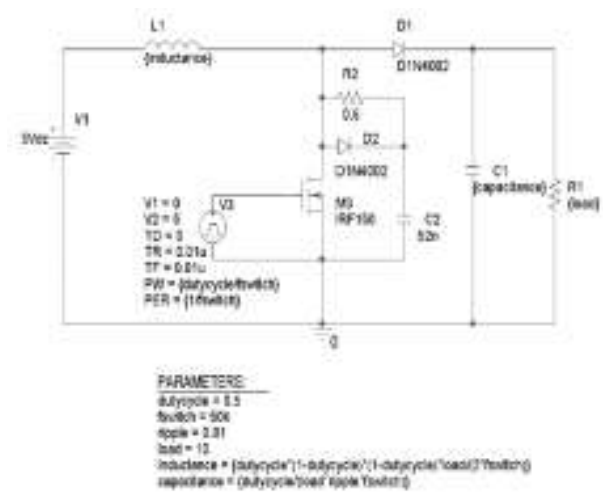

Figure 5: Boost Converter with snubber circuit 


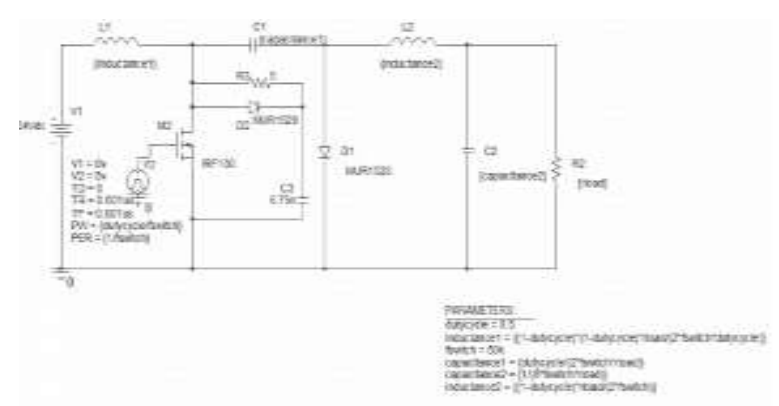

Figure 6: Cuk Converter with snubber circuit

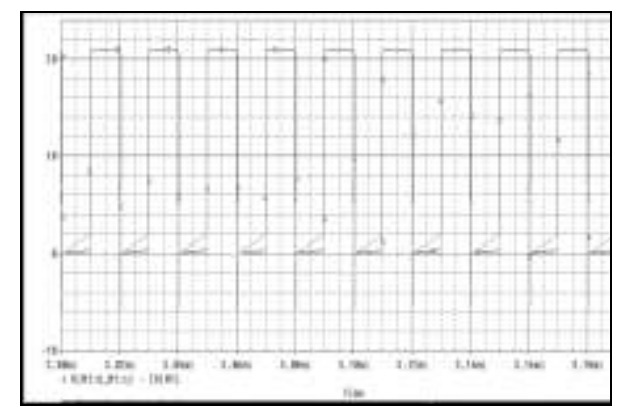

Figure 7: Voltage across drain and source of MOSFET and current across drain (Buck Converter)

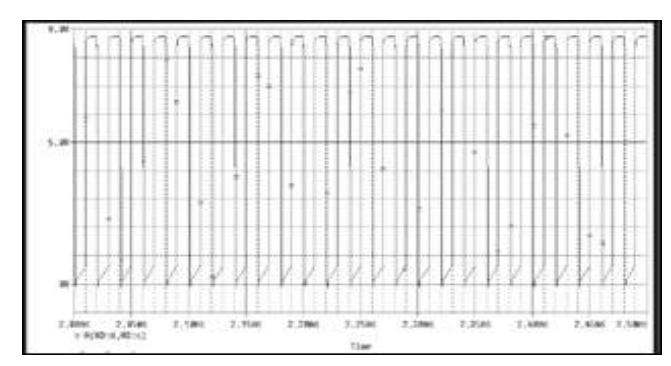

Figure 8: Voltage across drain source of the MOSFET (Boost Converter) without snubber circuit.

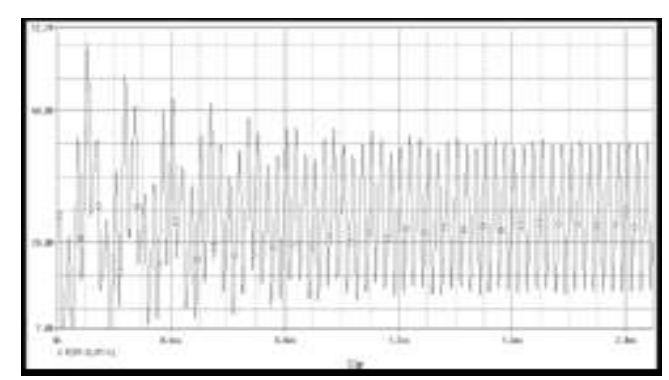

Figure 9: $\mathrm{V}_{\mathrm{d}}$ for $30 \mathrm{MHz}$ without snubber circuit

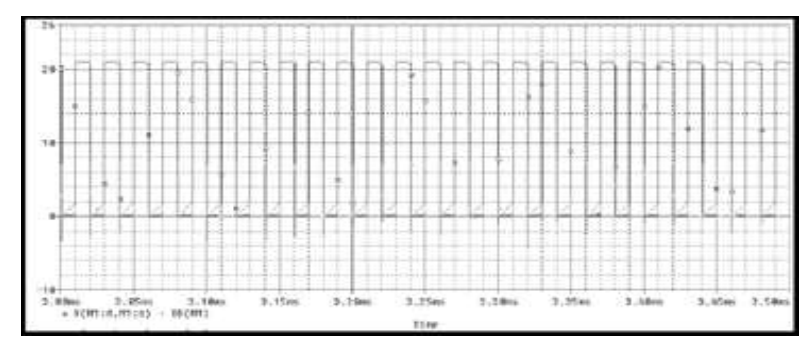

Figure 10: Voltage across drain and source of MOSFET and current across drain with snubber (Buck Converter)

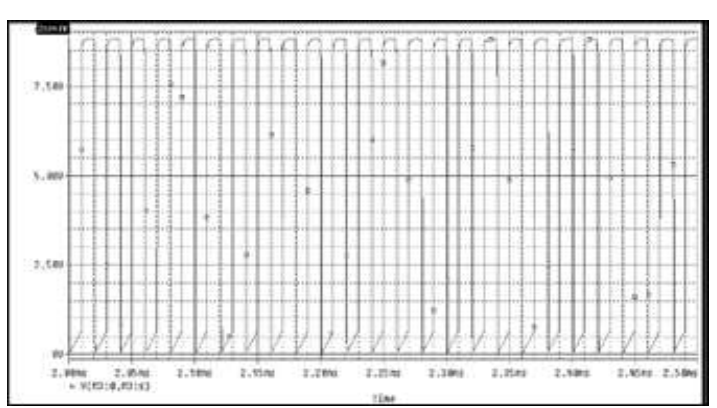

Figure 11: Voltage across drain source of the MOSFET (Boost Converter) with snubber.

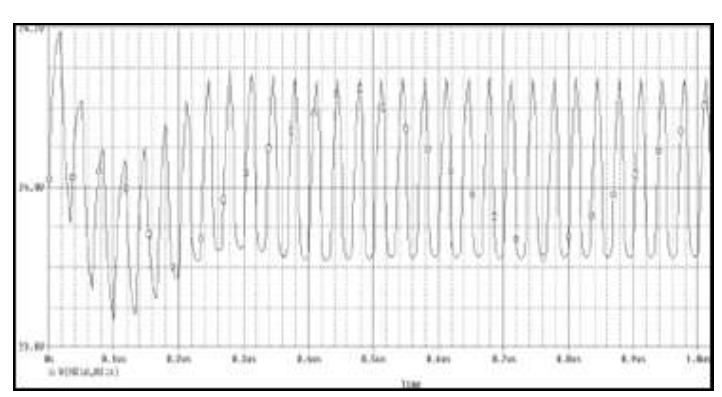

Figure $12: \mathrm{V}_{\mathrm{d}}$ for $30 \mathrm{MHz}$ with snubber circuit (Cuk Converter)

Table 1. Buck Converter without Snubber

\begin{tabular}{|c|c|c|c|c|c|c|c|}
\hline $\begin{array}{c}\text { Ireguen } \\
\text { y }\end{array}$ & (A) & (i) & $\begin{array}{l}P_{b} \\
\text { (M) }\end{array}$ & $V_{L}$ & $f_{j}$ & $L_{(A)}$ & $(0)$ \\
\hline $9 \mathrm{kHz}$ & 72961 & 2126 & 151328 & 20.011 & 72916 & 343 & 13.113 \\
\hline $5 \mathrm{C} \mathrm{kHz}$ & 72092 & 21.102 & 151379 & 2005 & 60351 & 1031 & 12003 \\
\hline $100 \mathrm{kHz}$ & 72085 & 21131 & 151.465 & 20.057 & 49632 & 0.822837 & 8.9284 \\
\hline $50 \mathrm{kHz}$ & 1315 & 210 & $1+2.184$ & 19.43 & 3624 & D.fRKAT & 1621 \\
\hline $1 \mathrm{NII}$ & 71099 & 70975 & $141 \mathrm{ing}$ & 19 9 970 & 34414 & 0712996 & 7129 \\
\hline $3 \mathrm{BH}_{2}$ & 64611 & 20861 & 13236 & 19.330 & 23272 & $0.5063^{2}$ & 5238 \\
\hline $5 \mathrm{WHz}$ & 32883 & 2072 & 96901 & 87738 & 0.7966101 & 0269728 & 25977 \\
\hline $2 \mathrm{WHz}$ & 117762 & 20668 & $38-78$ & 68676 & 0.576177 & 1210212 & 21021 \\
\hline 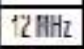 & 16145 & (2) it & $J_{i}{ }^{2}+4$ & $4.282 ?$ & Qbive & 1.211115 & 21511 \\
\hline 5 圌, & $19 \mathrm{nt}$ & 20619 & 27104 & 3774 & $0502 x$ & 12501:2 & 2901 \\
\hline 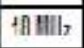 & 12,121 & ger & 97904 & 9ents & 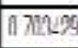 & $1510 \%$ & $5 \mathrm{mpr}$ \\
\hline $21 \mathrm{MH}_{2}$ & 1445 & 20568 & 2838 & 25043 & 0.937609 & 0.770235 & 77025 \\
\hline $24 \mathrm{MH} 2$ & $1 / 4015$ & 20508 & 28600 & 2623 & 126.2 & 191 & 11.111 \\
\hline $27 \mathrm{NHz}$ & $1.167 ?$ & 20337 & J1.191 & 26914 & 18688 & .6711 & 12.711 \\
\hline 301012 & 22435 & 20326 & J/.611 & 21236 & 22011 & Fict3 & $132+2$ \\
\hline
\end{tabular}

Table 2. Buck converter With snubber 


\begin{tabular}{|c|c|c|c|c|c|c|c|}
\hline & $I_{d(A)}$ & ब(ग) & $P_{2 \pi}$ & $f_{L(0)}$ & $I_{L(A)}$ & {$[(t)$} & \\
\hline $9 \mathrm{kHz}$ & 72775 & 21256 & 150297 & 19997 & 72691 & t3. 121 & 13121 \\
\hline $60 \mathrm{bHz}$ & 7.1956 & 20959 & 499.978 & 19.594 & 6.1153 & 51.132 & 10122 \\
\hline 0.16Hz & 7.165 & 21135 & 49.005 & 19.991 & 50765 & 89542 & $0.0954^{2}$ \\
\hline blte & $7 \%$ & 21019 & 48.505 & 19.916 & 76529 & 77957 & 077957 \\
\hline $\mathrm{IHz}$ & 71415 & 20973 & 147.623 & 19.637 & 34013 & 72101 & $07210^{1}$ \\
\hline $\mathrm{HHz}$ & 6.462 & 20853 & 132401 & 18.787 & $220 \%$ & 56268 & 0.56157 \\
\hline IHz & 32243 & 20719 & 66006 & 69602 & 0847337 & 32539 & 5 \\
\hline IHI & 20087 & 20651 & 40951 & 421 & $039797 ?$ & 28700 & 0.28701 \\
\hline 2) $\mathrm{NHz}_{\mathrm{H}}$ & 14324 & 20628 & 30135 & 3.1979 & 0542661 & 32263 & 032962 \\
\hline $\mathrm{Hz}$ & 1378 & 20675 & 28.18 & 2683 & 055520:5: & 40204 & 0.40368 \\
\hline $\mathrm{WH}_{\mathrm{H}}$ & 13022 & 20574 & 26976 & 25101 & 0635222 & 5.745 & 0.57 .450 \\
\hline Whz & 1.2434 & 20222 & 25402 & 23937 & 0995161 & 83513 & 0.82512 \\
\hline & 1.3984 & 2024 & 26394 & 2351 & 12678 & 11.122 & $1: 122$ \\
\hline & 1.8034 & 20224 & 3259 & 24721 & 1813 & 16006 & 16916 \\
\hline 614 & 22281 & 20232 & 36.354 & 25989 & 21875 & 19.158 & 19188 \\
\hline
\end{tabular}

Table 3. Boost converter Without snubber

\begin{tabular}{|c|c|c|c|c|c|c|c|}
\hline fourzer & VLIV & $L(A)$ & $b s i(v)$ & {$[z(A)$} & (bsasini) & $\operatorname{Vot} \mid \mathrm{Y}$, & bos:(n4) \\
\hline 3:Hz & 58998 & $7.2 \mathrm{~L}$ & 5.396 & 7,42 & 70.85 & 356 & 896.08 \\
\hline $50 \mathrm{HHT}$ & 5.77807 & 631. & $8 \pi 7$ & 7.59 & 60.92 & 7.73 & 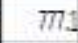 \\
\hline 10J6ht? & 56613 & 532 & $7 \pi 61$ & 7.23 & 53.6 & $5 \pi$ & 677,12 \\
\hline 503kH: & 5.757 & 4,73 & 5.402 & 7.149 & 36.31 & 436 & 125 \\
\hline 1 the & 52047 & 4253 & 5.343 & 7.13. & 36.61. & 4514 & 51 \\
\hline $3 \mathrm{M}-2$ & 1828 & $3573 \mathrm{a}$ & 5.397 & 6.439 & 33.25 & $463:$ & 639: \\
\hline $5 \mathrm{Mh}-\mathrm{z}$ & 6.398 & $1952:$ & 5.2396 & $37 \pi$ & 1904 & 4,63 & 36.67 \\
\hline $3 \mathrm{H}-2$ & 0.25 & 1.4557 & 5.1303 & $24: 4$ & 1200 & 4.278 & \\
\hline $12 \mathrm{M}-\mathrm{z}$ & 0.213 & 13453 & 5.1522 & 1.8767 & 9.35 & 4.54 & \\
\hline $15 \mathrm{MH}-\mathrm{z}$ & 0.213 & 1.459 & 5.167 & 1.7 & 865 & 4.2558 & \\
\hline $18 \mathrm{M}-\mathrm{z}$ & 1.238 & 15773 & 5.1353 & 1724 & 873 & ALIE] & \\
\hline $21 M-2$ & $0.2 \pi$ & 1.914 & 5.2173 & $1877 \pi$ & 9.54 & 43064 & \\
\hline $24 \mathrm{M}-2$ & (3.34) & 23875 & 52582 & 2.244 & 1088 & 43558 & \\
\hline $271 M-2$ & 0.52 & 30535 & 53281 & 2.5559 & 13.2 & $4 \angle C C E$ & \\
\hline $30 \mathrm{Mi}-2$ & 0.524 & 3.4524 & 53352 & 2966 & 15.1 & 44278 & 4272 \\
\hline
\end{tabular}

Table 4. Boost Converter With snubber

\begin{tabular}{|c|c|c|c|c|c|c|c|}
\hline foute & 12. $|y|$ & $|L| A \mid$ & VesiV| & $t: \mid A\}$ & $\cos \alpha \mathbf{w}$ & $\operatorname{Sor}[(])$ & $\left|\operatorname{sot}(n)^{\prime}\right|$ \\
\hline$k$ & 50.5 & 7.25 & 5996 & 721 & 68.58 & 3961 & $8 \% 1$ \\
\hline $00 \mathrm{kt}$ & j.15: & 6.25 & 88 & 217 & $62 x$ & 7800 & 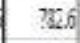 \\
\hline $100102-2$ & 5.123 & 5.248 & 7.55: & 7165 & 34 & $58 \mathrm{~A}$ & 6245 \\
\hline $0030 \mathrm{Tt}$ & 48. & $4 X 2$ & 5,45 & 7.143 & 36.54 & 44 & 4LIII \\
\hline $1 \mathrm{NHz}$ & 4753 & 4,463 & 53502 & 7.155 & 37,2 & 458: & 458.3. \\
\hline ENh & 2803 & 3562 & $5: 591$ & 6.227 & $3: 2$ & 4661 & 25312 \\
\hline ENh & 1978 & {$[947$} & 5.271 & 3719 & $28 \pi$ & 434 & 23435 \\
\hline ENHz & 224 & 245 & 5.190 & 2398 & 123 & 4289 & 423.3 \\
\hline $120 \mathrm{H}$ & 2.19: & 1.327 & 5154 & 1375 & 9.35 & 5154 & 5i5. \\
\hline $15 \mathrm{w}-2$ & 2200. & 1244 & 5.154 & 174 & B.F: & 427 & 42473 \\
\hline $18 \mathrm{H}-\mathrm{z}$ & 222 & 1578 & 5.1600 & 1.63 & 8.31 & 485 & 42.32 \\
\hline Lull: & 0.38 & 292 & S.LE: & 1399 & 9.24 & 4200 & $423 \pi$ \\
\hline $24 \mathrm{H}-2$ & 1233 & 243 & $52 x$ & 2139 & $103:$ & 4327 & 4227 \\
\hline awh & 1.4 & 3.122 & $5.31:$ & 25380 & 12.24 & 4.406 & 20456 \\
\hline $20 \mathrm{wh}-\mathrm{z}$ & 2.77 & 3.5 .4 & 5.306 & 30098 & 35.15 & 4.99 & 47.38 \\
\hline
\end{tabular}

Table 5. Cuck Converter without Snubber

\begin{tabular}{|c|c|c|c|c|c|c|c|}
\hline tequercy & Volts 10 & $f|d| a m p s$ & Wodts & II. Amp & 5/|Vot|Vot: & 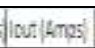 & Pones \\
\hline intz & 75.673 & 537 & 2416 & 2287 & (6)3:3 & 1337 & 52741 \\
\hline $2 \mathrm{kHz}$ & 75935 & 6895 & 24161 & $2 \%$ & 4427 & 1777 & 225566 \\
\hline Whith & 70.05 & $8 \mathrm{~m}$ & 2421 & 211 & 1334 & 1.739 & 6424 \\
\hline $203 \mathrm{KHz}_{2}$ & 7592 & $10: 58$ & 24172 & 207 & 10.23 & $1.57 ?$ & 108155 \\
\hline $111+2$ & T355 & 1239 & 2414 & 2118 & 346 h & 138 & Hisseg \\
\hline INtz & $11 \%$ & 6241 & 24015 & 2231 & $19: 212$ & 0.77745 & 47426 \\
\hline inth & 69.577 & 4776 & $23 \%$ & 2583 & 1277 & 0.589861 & 31927 \\
\hline 3ittz & 6752 & 3384 & 23991 & 2919 & 12179 & 0.433148 & 293607 \\
\hline $211-t$ & $6+513$ & 3153 & 2385 & 3.179 & 11454 & 0.458865 & 24175 \\
\hline $511+t$ & 6.84: & 3712 & 2981 & 345 & 1016 & 0.432196 & 25042 \\
\hline $311-t$ & $569 \%$ & $3 \mathrm{n} 1$ & 23851 & 3621 & 1025 & 0.40154 & 221515 \\
\hline $2111 / \mathrm{t}$ & 36122 & $3 \mathrm{mi}$ & 23743 & 3779 & 9699 & 033774 & 213655 \\
\hline $4+1 / 2$ & 57333 & 1115 & 23712 & $30 \% 5$ & 9123 & 032964 & 293.141 \\
\hline $271 / t$ & $57: 099$ & 3959 & 23166 & $3: 533$ & 75 & 0300066 & 2500 \\
\hline $231-2$ & 30346 & $3: 42$ & 22741 & 297 & 5751 & 023465 & 151258 \\
\hline
\end{tabular}

Table 6. Cuk Converter With Snubber

\begin{tabular}{|c|c|c|c|c|c|c|c|}
\hline Frequency & $V_{\text {da }}$ Notss & $4 \mid$ Ampos & $V_{L}$ Volss & W. |Amps| & $\mathrm{V}_{\text {out }}(\mathrm{Nelts}$ & out $1 \mathrm{Amgs}$ & power \\
\hline ente & $76: 137$ & 3,547 & 24029 & 2.18 & 4.69 & 1738 & 200058 \\
\hline $00 \mathrm{htz}$ & 75.034 & 3356 & 24024 & 2069 & 49.367 & 1735 & 261958 \\
\hline $100 \mathrm{kHz}$ & 73.599 & 3117 & 23996 & 2007 & 41.473 & 1658 & 242128 \\
\hline $500 \mathrm{kHz}$ & 3281 & 2359 & 23832 & 1973 & 32560 & 13 & 199572 \\
\hline $1 \mathrm{MHz}$ & 51678 & 2772 & 23.79 & 1839 & 21.8 & 0872003 & 144.934 \\
\hline $3 \mathrm{HHz}$ & 37.469 & 2165 & 17299 & 1334 & 7214 & 0.236564 & 61.07 \\
\hline $5 \mathrm{NHZ}$ & 27.874 & 1306 & 6107 & 0,521532 & 1.79 & 0071599 & 38.634 \\
\hline gurz & 25.627 & 0766332 & 2954 & 0256241 & 0.776639 & 0036634 & 18.102 \\
\hline $121,1, k z$ & 24.521 & 0.14248 & 1676 & 0.153645 & 0.462272 & 0016091 & 3452 \\
\hline $15 \mathrm{Nht}$ & 24561 & 0265652 & 091556 & 0.998567 & 0.216513 & 00066551 & 6.532 \\
\hline 18 arte & 24.36 & $0.1779 \%$ & 0.5534 & 0063475 & 0.12238 & 00044903 & 4315 \\
\hline $21 \mathrm{whz}$ & $2+28$ & 0.12378 & 0.32968 & 0004697 & 0.076 .54 & 0.023132 & 2505 \\
\hline $2+1 / 1 / 2$ & 24219 & 0090195 & 0.20743 & 000328 & 0.057545 & 0012025 & 2184 \\
\hline VDWHZ & 24,193 & $0.669 \% 7$ & 0.17664 & 0024993 & 0.05107 & 0012005 & 1562 \\
\hline $301,1, t z$ & 34.196 & 10.554919 & 0.16729 & 00187766 & 10.045787 & 001832 & 1.326 \\
\hline
\end{tabular}

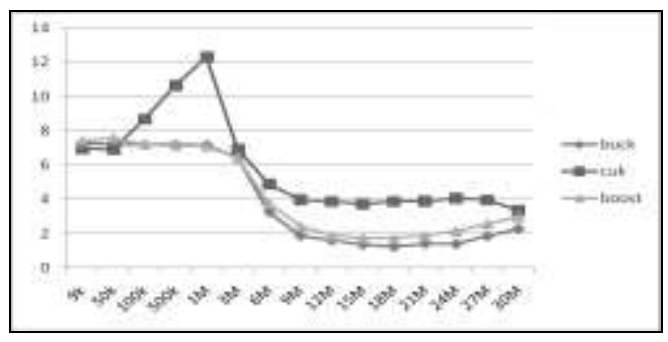

Figure 13: $I_{d}$ without snubber

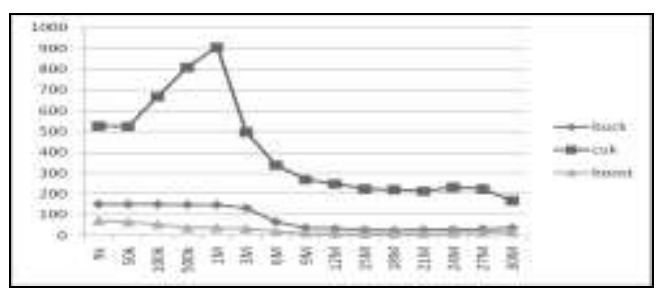

Figure 14: $\mathrm{P}_{\mathrm{d}}$ without snubber 


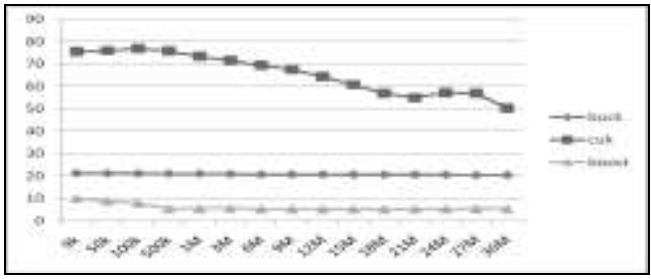

Figure 15: $\mathrm{V}_{\mathrm{d}}$ without snubber

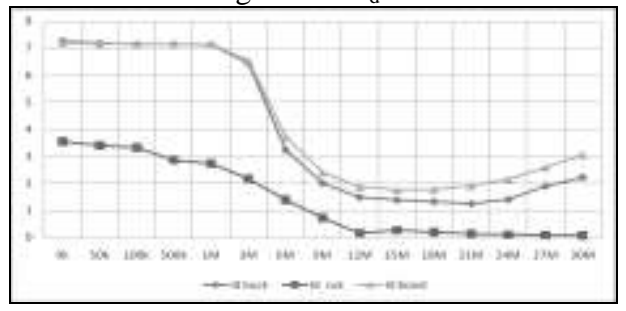

Figure 16: $I_{d}$ with snubber

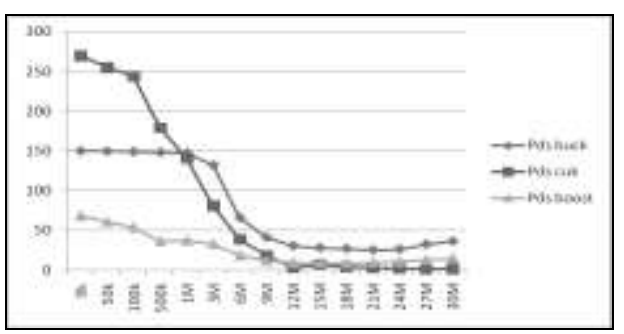

Figure 17: $\mathrm{P}_{\mathrm{d}}$ with snubber

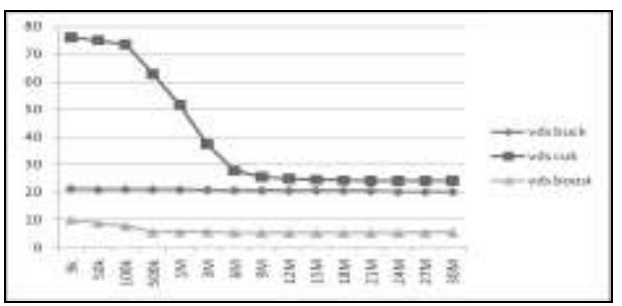

Figure 18: $\mathrm{V}_{\mathrm{d}}$ with snubber

\section{Analysis}

From Figure 13, the drain current of buck, boost and Cuk converter is almost maintained for lower frequency ranges from $9 \mathrm{kHz}$ to $1 \mathrm{MHz}$. In the range of $3 \mathrm{MHz}$ to $30 \mathrm{MHz}$ there is a drastic reduction in the values of drain current. The $d i / d t$ effect of Cuk converter is of high value in the frequency range of $500 \mathrm{kHz}$ to $3 \mathrm{MHz}$ The operation of Cuk converter is not suitable for the switching frequency ranges from $500 \mathrm{kHz}$ to $3 \mathrm{MHz}$, due to the high value of $d i / d t$ and power loss. The sudden rise in the current level will generate EMI.

From Figure 16, the effect of snubber is visualized by the significant reduction of drain current in the range of $500 \mathrm{kHz}$ to $3 \mathrm{MHz}$ and overall reduction of drain current for all the frequency ranges.

From Figure 15, it is identified that the voltage drop across the switch $\left(\mathrm{V}_{\mathrm{ds}}\right)$ is very high when compared to buck and boost converter. It is also found that the $\mathrm{V}_{\mathrm{ds}}$ is almost constant for the increasing switching frequencies of buck and boost converter.
From figure 18, it is found that by using RCD snubber the voltage drop across the switch is reduced for the switching frequencies ranges from $6 \mathrm{MHz}$ to $30 \mathrm{MHz}$

It is evident from Figure 13 and 15 the Cuk converter is not suitable for low frequency ranges, unless otherwise the implementation of proper snubber circuit.

Comparing the Figure 14 and 17 it is proved that the power loss is reduced by connecting a snubber circuit and it is also inferred that the Cuk converter is much suitable for the switching frequency ranges from $6 \mathrm{MHz}$ to $30 \mathrm{MHz}$.

\section{CONCLUSION}

This paper aimed to simulate and compare the three topologies namely the buck, Cuk, Boost and also compare the effect of a RCD snubber on each of these topologies. The converters were analyzed for different switching frequencies ranging from $\quad 9 \mathrm{KHz}-30 \mathrm{MHz}$.It was also observed from the analysis that EMI is produced due to high switching frequency of the MOSFET. In order to reduce the EMI and increase the efficiency the RCD snubber is used and the following was found:

1. It was analyzed that the snubber was very much useful in reducing both the current and voltage spikes efficiently in the buck and Cuk converters.

2. It was found that the power loss of the converter with the snubber was smaller than that without the snubber circuit.

3. It was analyzed that the RCD snubber was not that effective in the mitigation of spikes of $V_{d}, I_{d}$ and power loss in the case of boost converter.

\section{REFERENCES}

[1] B.W Williams, Power Electronics Devices, Drives and Application, MacMillan Education Ltd. London.1987.

[2] N. Mohan, T.M. Undeland and W.P. Pobbons, "Power Electronics Converters Applications and Design", Second edition, John Wiley and Sons: Singapore, Inc. 1995.

[3] W. McMurray, "Selection of Snubbers and clams to optimize their design of transistor switching converters". IEEE rans.Ind.Appl.,Vol.[A-16.pp.513-523,July/Aug, 1980.

[4] M.H. Rashid. "Spice for Power Electronics and Electric Power”. Prentice Hall, Englewood Cliffs, New Jersey 1993.

[5] Oto Tezak,Drago Dolinor, and Miro Milanovie, " Snubber Design Approach for DC-DC Converter Based on Differential Evolution Method" IEEE Conference AMC 2004, pp 87-91. Kawasaki, Japan.

[6] Shao j., Lin, R.L., Lee, F.C. and Chan, D.Y. "Characterization of EMI Performance for Hard and Soft Switched Inverters". Applied Power Electronics Conference and Exposition.2000 APEC2000. Fifteenth Annual IEEE Vol.2, 2000 pp. 1009-1014

[7] W.Teulings, et al., A new technique for spectral analysis of conducted noise of a SMPS including interconnects, proceedings of IEEE PESC 1997, pp. 1516-1521.

[8] S.Kaitwanidvilai,K.unchaleevara pan, B. Hutawarakornand Y. Prempraneerach, "The Effect of Switching Frequency and duty cycle on SMPC Conducted Emission: Simulation and Experimental", IPEC '99 Conference Proceedings 1999, vol. 1,pp. 667- 672.

[9] Kenichiro Fujiwara and Hiroshi Nomura, "A Novel Lossless Passive Snubber for Soft-Switching Boost-Type 
Converter",IEEE Trans. Power Electronics, vol. 14, no.6, 1999,pp.1065- 1069.

[10] H.P. Yee, “An EMI Suppression MOSFET Driver”, Applied Power Electronics Conference and Exposition, APEC '97 Conference Proceedings 1997, 12th Annual, 1997, vol.1,pp. 242-248.

[11] W.Khan-ngern "Electromagnetic Compatability Experimental Laboratory on Power Electronics" ICEMC 2002/Bangkok 406-411.

[12] John C. Fluke, Sr, "Controlling Conducted Emissions by Design," Van Nostrand Reinhold,1991,pp.49-63.

[13] C. U-Yaisom, V.Tarateeraseth,W.Khan-ngern, S. Nitta" The Analysis of Mixed Series and Parallel Snubbers to reduce Conducted EMI Emission on a Switching Converter"IEEE conference.

[14] Kenichiro Fujiwara and Hiroshi Nomura, " A Novel Lossless Passive Snubber for Soft-Switching Boost-Type Converter" IEEE Trans. Power Electronics, Vol. 14, no.6, 1999, pp.1065-1069.

[15] J.D Van Wyk, Fred C.Lee Power electronics technologystatus and future, Proceedings of IEEE PESC 1999, pp 3-12.

[16] Shao j., Lin, R.L., Lee, F.C. and Chan, D.Y. "Characterization of EMI Performance for Hard and Soft Switched Inverters". Applied Power Electronics Conference and Exposition.2000 APEC2000. Fifteenth Annual IEEE Vol.2, 2000 pp. 1009-1014

[17] Andrzej M. Trzynadlowski, "Introduction to Modern power electronics".

\section{AUTHOR PROFILE}

[1] Mr. Krishna Kumar, born on the year 1973, in Kumbakonam, India. He received the degree of B.E., and M.Tech from Bharathidasan University and SASTRA University in 1994 and 2002, respectively. He is doing his research program in ANNA University, Coimbatore.
He researches in the area of EMI on Power Converters. Presently he is working for Periyar Maniammai University, Vallam, Thanjavur as Assistant Professor (ss) in the Department of Electrical and Electronics Engineering.

[2] Dr.A.Nirmal Kumar, Head of Electrical and Electronics Engineering Department in Bannari Amman Institute of Technology,Sathyamangalam completed his graduation and post graduation in Electrical Engg. from Calicut and Kerala University respectively. Completed his Doctorate from Bharatiar University in Power Electronics. He has more than 30 years of teaching experience. He is guiding at present 20 research scholars. He is the recipient of Institution of Engineers Gold Medal for the year 1989. He has many publications in national and international journals to his credit.

[3]. Mr.B.Karthikeyan born on the year 1974, in Thanjavur, India. He received the degree of B.E., and M.Tech from Bharathidasan University and ANNA University, Chennai in 1996 and 2000, respectively. He received his ph.D., from SASTRA university Thanjavur. He is interested in the area of EMI on Power Converters. Presently he is working as Associate professor for BITS Dubai campus in the Department of Electrical and Electronics Engineering.

[4] R.Abinaya was born in the year 1989, in Thiruvarur, India. She completed B.E in Periyar Maniammai College of technology for women, Vallam, Thanjavur and now doing M.Tech in SRM University, Chennai. 